\title{
Q\&A: Museum's metamorphosis is nearly complete
}

On the unveiling of the second phase of the Darwin Centre at London's Natural History Museum, Anna Maria Indrio, partner at the Scandinavian architectural firm C. F. Møller, explains how the new $£ 78$ million (US $\$ 145$ million) wing will reveal 20 million of the museum's insect and plant specimens to the public when it opens in September 2009.

\section{What were the design challenges?}

The biggest issue was the huge size of the collections, which are among the world's most extensive and treasured. Protecting such a valuable array of 17 million insects and 3 million plants in 3 kilometres of cabinets, showcasing them to the public and ensuring that the design represents the scientists' work was very daunting.

\section{How are the specimens shielded?}

A cocoon - representing preservation, protection and nature - forms the inner envelope of the building. Shaped according to mathematical equations, it is 8 storeys high, 65 metres long and is the largest sprayed-concrete curved structure in Europe. The hand-finished surface of ivory-coloured polished plaster resembles a silk cocoon; a series of expansion joints wrap around like silk threads. To emphasize the massive scale of the collections, the giant cocoon can never be seen in its entirety.

\section{How will the public experience the Darwin Centre?}

Around 2,500 visitors per day will journey through a series of exhibits within the cocoon. They will be able to watch scientists at work in glass-fronted laboratories through windows at the end of the cocoon. And through naturalhistory films, new media and face-to-face encounters with museum scientists, visitors will be inspired to be naturalists observing the natural world and debating our relationships with it.

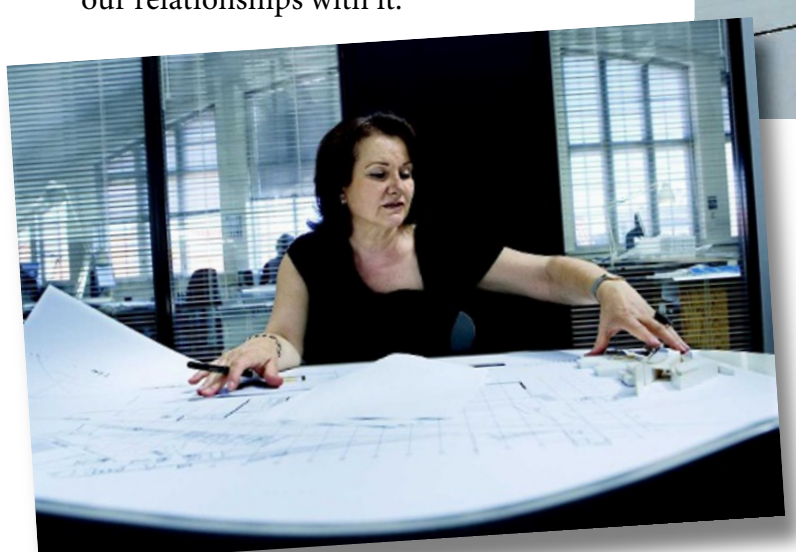

\section{What research facilities are included?}

More than 200 scientists will be able to work in the centre at any one time in purpose-built laboratories, doubling the research space at the museum. Its open-plan layout is designed to help the exchange of ideas. The eighth-floor common room will be shared across all the life-science departments.

\section{How will you feel when it opens?}

We discovered an astonishingly complex world at the museum, with many layers to the design brief. We will be hugely proud when the scientists start moving in early next year.

Interview by Joanne Baker, Nature's Books \& Arts Editor. information.

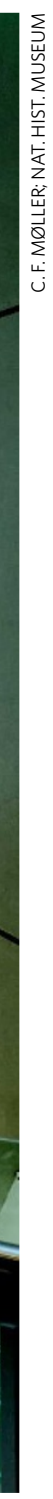

